ISSN 0103-5150

Fisioter. Mov., Curitiba, v. 29, n. 3, p.439-448, Jul./Set. 2016

Licenciado sob uma Licença Creative Commons

DOI: http://dx.doi.org.10.1590/1980-5918.029.003.A001

(c) (i)

\title{
Multifactorial assessment of the risk of falls in low bone density older women
}

\author{
Avaliação multifatorial do risco de quedas em \\ idosas com baixa densidade óssea
}

\author{
Patrícia Azevedo Garcia ${ }^{[\mathrm{a}]}$, João Marcos Domingues Dias ${ }^{[\mathrm{b}]}$, Rosane Liliane dos Reis $^{[\mathrm{a}]}$, \\ Rosângela Corrêa Dias ${ }^{\left[\mathbf{b}^{*}\right.}$ \\ [a] Universidade de Brasília (UnB), Brasília, DF, Brazil \\ [b] Universidade Federal de Minas Gerais (UFMG), Belo Horizonte, MG, Brazil
}

\begin{abstract}
Introduction: Identifying effective assessment instruments for predicting falls, specifically in older women with low bone mineral density (BMD) that are more susceptible to fractures remains a challenge. Objective: To evaluate risk factors for falls at baseline, to identify the falls occurrence over six months of follow-up and to investigate the predictive validity of the Quickscreen Clinical Falls Risk Assessment for predicting multiple falls among low BMD older women. Methods: A methodological study with 110 older women with diagnosis of osteoporosis or osteopenia (70.26 \pm 6.24 years). The presence of two or more of the eight risk factors assessed by the QuickScreen characterized the risk of falling (baseline) and monthly phone calls identified the occurrence of falls during the six months of follow-up. Results: The most prevalent falls risk factors were self-reported previous falls, polypharmacy and impairment in shifting weight and lateral instability. Most of the older women (67.3\%)
\end{abstract}

\footnotetext{
*PAG: PhD, e-mail: patriciaagarcia@unb.br JMDD: PhD, e-mail: jmdd@ufmg.br

RLR: undergrad, e-mail: rosane_liliane@hotmail.com

RCD: PhD, e-mail: rcd@ufmg.br
} 
had two or more risk factors, $24.5 \%$ reported a single fall and $13.6 \%$ reported multiple falls over the six months. The QuickScreen (cutoff $\geq 2$ risk factors) showed good sensitivity (73.3\%) and high negative predictive value (88.89\%) for predicting multiple falls among low BMD older women. Conclusions: The results indicated a high frequency of falls among low BMD older women. Additionally, the results highlighted that the QuickScreen instrument was able to predict multiple falls in the six months of follow-up among these older women.

Keywords: Aged. Bone Density. Osteoporosis. Accidental Falls. Mass Screening.

\section{Resumo}

Introdução: A identificação de instrumentos de avaliação eficazes na predição de quedas, especificamente em idosas com baixa densidade mineral óssea (DMO) e mais susceptíveis a fraturas, permanece um desafio. Objetivo: Avaliar os fatores de risco para quedas na linha de base, identificar a ocorrência de quedas em seis meses de acompanhamento e investigar a validade preditiva do teste Quickscreen Clinical Falls Risk Assessment para predizer quedas múltiplas em idosas com baixa DMO. Métodos: Estudo metodológico com 110 idosas com diagnóstico de osteoporose ou osteopenia (70,26 $\pm 6,24$ anos). O risco de queda (linha de base) foi caracterizado pela presença de dois ou mais dos oito fatores de risco avaliados no QuickScreen e a ocorrência de quedas nos seis meses posteriores identificada por meio de telefonemas mensais. Resultados: Os fatores de risco para quedas mais frequentes foram o autorrelato de quedas prévias, a polifarmácia e o déficit de deslocamento de peso e instabilidade lateral. A maioria das idosas (67,3\%) apresentou dois ou mais fatores de risco, 24,5\% relataram uma queda e 13,6\% quedas múltiplas nos seis meses. O QuickScreen (ponto de corte $\geq 2$ fatores de risco) apresentou boa sensibilidade (73,3\%) e alto valor preditivo negativo (88,89\%) para predizer quedas múltiplas em idosas com baixa DMO. Conclusão: Os resultados indicaram alta frequência de quedas entre idosas com baixa DMO e apontaram que o instrumento QuickScreen foi capaz de prever quedas múltiplas em seis meses de acompanhamento nessas idosas.

Palavras-chave: Idoso. Densidade Óssea. Osteoporose. Acidentes por Quedas. Programas de Rastreamento.

\section{Introduction}

Osteoporosis is an metabolic bone disorder, more common in women, characterized by reduced bone mineral density (BMD) below the fracture threshold (1), which affects more than 5.5 million people in Brazil (2). Osteoporosis can cause postural changes due to vertebral fractures, impairments in static and dynamic balance and in the transposition of obstacles, reduced physical performance and psychosocial changes (3 - 5), which contribute to higher prevalence of falls in older women with this diagnosis (6) and increase the risk of fractures. Approximately 95\% of hip fractures are related to falls and at least $40 \%$ of osteoporotic older women over 70 years of age have suffered a fracture due to falling (7). Fractures have a direct impact on the quality of life of these older women because they are disabling events that can lead to functional dependence, hospitalization, institutionalization and death.

Aiming to help in the early recognition of the risk of falls, in the therapeutic decisions and in planning more assertive prevention activities for older women with low BMD, researchers have directed efforts to determine the predictive validity of instruments that identify the risk of falls in diverse populations, considering their particular characteristics $(3-6,8,9)$. A fall is defined as an unintentional event that results in the change of the position of the individual to a lower level relative to their initial position (10), excluding the result of a violent blow, falls in which the individual holds onto a wall or another structure, high-impact crashes and falls due to loss of consciousness or sudden paralysis (11). However, given the multifactorial nature of falls, currently no instrument applied in isolation has been shown to identify the risk of falls in older adults (12). Although many instruments have been introduced into the clinical practice in recent years, the challenge remains, as these inclusions were not based on solid evidence regarding their capacities to discriminate older adults with and without the risk of falls and some tests have not yet been extensively evaluated (12). 
In this sense, the combination of instruments contained in the comprehensive functional assessment of the recently published Quickscreen Clinical Falls Risk Assessment (QuickScreen) clinical test (13), approached the multifactorial characteristic of the risk of falls and was shown to be predictive of falls in the original validation study with older adults, living in the community (13). However, studies of analysis of the predictive accuracy for falls of this instrument in different scenarios and in specific groups with higher risks for falls and fractures are still lacking. In this context, in order to test whether this instrument is able to successfully identify the risk of multiple falls among low BMD older women, this study aimed to evaluate the risk factors for falls at baseline, to identify the occurrence of falls during six months of follow-up and to investigate the predictive validity for multiple falls of the QuickScreen test in older women with low BMD.

\section{Methods}

Type of Study and Ethical Aspects

This was a methodological study approved by the Research Ethics Committee of the Universidade Federal de Minas Gerais (CAAE 0370.0.203.013-11) in accordance with Resolution 196/96 of the National Health Council and was performed at the Laboratório de Análise de Movimento of a higher education institution. All participants signed an informed consent form.

\section{Sample}

The study included 110 older women $(70.26 \pm 6.24$ years), living in the community, selected by convenience in older adult health care programs. This study configured part of a major study (doctoral thesis (14) that aimed to evaluate the risk factors for falls among women with low BMD and that estimated a sample size of 94 older women for the regression analysis. In order to avoid prejudice to the statistical validity regarding losses of participants, 127 older women were recruited (35\% increase). The inclusion criteria were being female, aged 60 years or over, with a previous diagnosis of osteopenia or osteoporosis of the femoral neck and/or L1-L4 segment, considering T-scores below -1.0 SD as the reference, in accordance with the criteria of the World Health Organization (1). Exclusion criteria were cognitive impairment in the Mini Mental State Examination (15) (MMSE $<17$ points) $(\mathrm{n}=1)$, physical inability to perform the evaluations $(n=1)$ or sequel of Stroke (3) (n=1). There were 14 losses of older women who did not attend the laboratory for the observed performance evaluations $(n=6)$ or were not located through the monthly phone calls during the six-months of the study $(n=8)$.

\section{Quickscreen Clinical Falls Risk Assessment}

The evaluation of the risk of falls of the participants was carried out using the Quickscreen Clinical Falls Risk Assessment (QuickScreen) instrument. This instrument, considering the model of the International Classification of Functioning, Disability and Health (ICF), investigates compromises in the domains of structure and function of the body (posture, balance, and postural and balance reactions), activities (mobility related to changing the basic position of the body and transferring one's position) and environmental factors (medication) (16), and therefore its predictive accuracy among low BMD older women may be different from the original validation, considering clinical, physical and functional characteristics of this population (3 - 6).

The QuickScreen is a tool proposed by Tiedemann (17), that characterizes a multifactorial validated assessment of the risk of falls in the general population of older adults (13), with minimal need for equipment, simple and fast application in the clinical setting and content without cultural bias (18). This is a test that, in the original validation study, demonstrated high power to discriminate older adults with multiple falls ( $\geq 2$ falls) from those with non-multiple falls (one or no falls) during the following year, and that covers the evaluation of eight risk factors: (i) history of previous falls, (ii) polypharmacy, (iii) use of psychotropic medication, (iv) visual acuity, (v) peripheral sensitivity, (vi) balance in the standing position, (vii) shifting of weight and lateral stability, and (viii) strength of lower limbs (17).

Initially the risk factors related to the occurrence of one or more falls in the previous 12 months, the use of four or more medications (excluding vitamins and food supplements) and the use of psychotropic medication were investigated (13). Visual acuity was evaluated using the Snellen chart showing the letter 
"E" in four different positions, with the older woman positioned at a distance of five meters from the chart, considering the inability to read all the letters to the $5^{\text {th }}$ line as indication of risk $(13,19)$. Peripheral sensitivity was evaluated with the older woman sitting without shoes and socks and eyes closed, using a single monofilament aesthesiometer (Semmes-Weinstein SORRI) of 4.0 grams (dark red). The monofilament was applied three times in the lateral malleolus of the ankle of the dominant member and presence of this risk factor was considered when the participant was unable to feel at least two of the three stimuli applied (13). Static balance was evaluated through the tandem stand test, guiding the older woman to remain for 10 seconds with eyes closed, barefoot, with one foot in front of the other (with a distance of $2.5 \mathrm{~cm}$ between the heel of the front foot and hallux of the back foot) and slightly spread laterally $(2.5 \mathrm{~cm})$. Displacement of weight and lateral stability were evaluated by means of the alternate-step test, with a request to perform eight steps, alternating right and left, on a $15 \mathrm{~cm}$ high step. The performance of this test was timed and 10 seconds used as the cutoff point for determining risk in this item. To infer the strength of the lower limbs the sit-to-stand test was used, in which the older woman was asked to stand up and sit down five times on a standard chair (43 cm height), as quickly as possible, with arms crossed at the chest. The measurement was performed from the time of the initial sitting position until after the participant complete five repetitions to the point of sitting again and the cutoff of $12 \mathrm{sec}-$ onds was used for risk indication (17). The evaluation of these items presented excellent (sit-to-stand test, alternate-step test and visual acuity test) and moderate (tandem stand position test and touch sensation test) test-retest reliability $(13,20)$.

At the end of the evaluation of the eight items the sum of the risk factors observed was calculated to characterize the older woman as: (i) with risk of falling ( $\geq 2$ risk factors) or (ii) without risk of falling ( $\leq 1$ risk factor).

\section{Procedures}

The first phase of the study (baseline) occurred in two locations: at the home of older woman and at the Laboratório de Desempenho Humano. In their homes, the older women not excluded in the MMSE were interviewed to collect the socio-demographic and clinical data through a form containing questions regarding bone densitometry findings, age, comorbidities, continuous use medications and regular practice of exercise in the previous four weeks $(21,22)$. So they were classified regarding the level of physical activity, using the Activity Adjusted Score (AAS) of the Human Activity Profile questionnaire (23), as inactive (AAS $<53$ ), moderately active (AAS $=53-74$ ) or active (AAS > 74). Later in the same week, in the Laboratório de Desempenho Humano, body mass and height measurements were carried out to calculate the Body Mass Index (BMI), and then the evaluations of performance of the QuickScreen test were made by examiners blinded to the clinical history and risk factors of the participants. Information on the occurrence of falls in the six months subsequent to the evaluations was collected through monthly phone calls, always made by the same evaluator. During the call the evaluator explained the definition of a fall used in the study and asked the question "in the previous month have you fallen any time? If so, how many times?". The number of falls was accounted at the end of the followup period of the study.

\section{Statistical Analysis}

Descriptive analyzes of the sociodemographic and clinical-functional variables were carried out. The number of older women with risk of falling ( $\geq 2$ risk factors) and without risk of falling ( $\leq 1$ risk factor) in the QuickScreen was obtained for each of the two outcomes: multiple fallers ( $\geq 2$ falls) and non-multiple fallers ( 1 or 0 falls) indicated by monthly monitoring of the occurrence of falls over six months (after the baseline). To analyze the sensitivity, specificity, positive predictive value (PPV) and negative predictive value (NPV) false-positive, false-negative, true negative and true positive cases were considered. A significance level of $5 \%$ was considered. Statistical analyzes were performed using the Statistical Package for the Social Sciences (SPSS) version 16.0.

\section{Results}

Data from 110 older women with low BMD at the femoral neck and/or L1-L4 segment (53.6\% osteopenic and $46.4 \%$ osteoporotic) were analyzed. The clinical and sociodemographic characteristics of the study participants are presented in Table 1. 
Table 1 - Clinical and sociodemographic characteristics of the volunteers $(n=110)$

\begin{tabular}{lcc}
\hline Variable & Percentage (Frequency) & Mean \pm SD \\
\hline Age (years) & - & $70.26 \pm 6.24$ \\
Education (years of study) & - & $3.67 \pm 2.99$ \\
Mini-Mental State Examination (score) & - & $23.84 \pm 3.08$ \\
Body mass index (kg/m²) & $64.5 \%(71)$ & $27.08 \pm 4.65$ \\
Diagnostic conclusion of BD in the femoral neck & $14.5 \%(16)$ & - \\
Osteopenia & $21.0 \%(23)$ & - \\
Osteoporosis & & \\
Normal & $44.5 \%(49)$ & - \\
Diagnostic conclusion of BD in the lumbar spine & $45.5 \%(50)$ & \\
Osteopenia & $10.0 \%(11)$ & - \\
Osteoporosis & & - \\
Normal & $76.4 \%(84)$ & - \\
Presence of self-reported comorbidities & $8.2 \%(9)$ & - \\
Cardiac comorbidities & $80 \%(88)$ & $3.44 \pm 1.31$ \\
Respiratory comorbidities & $51.8 \%(57)$ & \\
Orthopedic comorbidities & - & - \\
Self-report of practice of regular exercise & & - \\
Frequency of regular exercise lasting $>30$ minutes (times per week) & $2.7 \%(3)$ & - \\
Level of Physical Activity (HAP) & $39.1 \%(43)$ & - \\
Inactive & $58.2 \%(64)$ & \\
Moderately Active & & \\
Active & & \\
\hline
\end{tabular}

Note: $\mathrm{BD}=$ Bone densitometry. $\mathrm{HAP}=$ Human Activity Profile questionnaire.

Table 2 presents the description of the risk factors evaluated by the QuickScreen and the occurrence of falls over six months in the older women of the study.

Table 2 - Description of the risk factors and the risk of falls evaluated in the QuickScreen Clinical Falls Risk Assessment test and the occurrence of falls in the sample over six months $(n=110)$

(To be continued)

\begin{tabular}{lcc}
\hline Risk Factors & Percentage (Frequency) & Mean \pm SD \\
\hline Self-report of one or more falls in the preceding year & $43.6 \%(48)$ & $2.27 \pm 2.39^{\star}$ \\
One fall & $21.8 \%(24)$ & \\
Two or more falls & $21.8 \%(24)$ & \\
Use of 4 or more medications & $63.6 \%(70)$ & - \\
Use of psychotropic medication & $28.2 \%(31)$ & - \\
Visual acuity impairment & $8.2 \%(9)$ & - \\
Peripheral sensitivity impairment & $1.8 \%(2)$ & - \\
Static balance impairment (tandem stand test) & $12.7 \%(14)$ & $10.45 \pm 3.79 \mathrm{~s}$ \\
Weight shift and lateral stability impairment (alternate-step test) & $41.8 \%(46)$ & $11.82 \pm 3.92 \mathrm{~s}$ \\
Muscle strength of the lower limbs impairment (sit-to-stand test) & $35.5 \%(39)$ & $2.35 \pm 1.53$ \\
Total Risk Factors & - & \\
Result of the QuickScreen test & & - \\
Negative test ( < 2 RF) & $32.7 \%(36)$ & - \\
Positive test ( $\geq 2$ RF) & $67.3 \%(74)$ & \\
\hline
\end{tabular}


Garcia PA, Dias JMD, Reis RL, Dias RC.

Table 2 - Description of the risk factors and the risk of falls evaluated in the QuickScreen Clinical Falls Risk Assessment test and the occurrence of falls in the sample over six months $(n=110)$

(Conclusion)

\begin{tabular}{lcc}
\hline Risk Factors & Percentage (Frequency) & Mean \pm SD \\
\hline Occurrence of falls over six months & & \\
Multiple falls & $13.6 \%(15)$ & $1.43 \pm 0.67^{*}$ \\
One fall & $24.5 \%(27)$ & \\
\hline
\end{tabular}

Note: $\mathrm{RF}=$ Risk Factors, *Values referring to the volunteers who presented one or more falls.

The results regarding the composition of the validity indices adopted in the study are presented in Table 3.

Table 3 - Composition of the validity indexes adopted in the study

\begin{tabular}{|c|c|c|c|}
\hline \multirow{2}{*}{$\begin{array}{l}\text { QuickScreen } \\
\text { test result }\end{array}$} & \multicolumn{2}{|c|}{ Occurrence of falls } & \multirow[t]{2}{*}{ Total } \\
\hline & $\begin{array}{l}\text { Multiple fallers } \\
\text { ( } \geq 2 \text { falls })\end{array}$ & $\begin{array}{l}\text { Non-multiple fallers } \\
\text { ( } 1 \text { or } 0 \text { falls) }\end{array}$ & \\
\hline Positive ( $\geq 2$ RF) & 11 & 63 & 74 \\
\hline Negative ( $<2 \mathrm{RF}$ ) & 4 & 32 & 36 \\
\hline Total & 15 & 95 & 110 \\
\hline
\end{tabular}

Note: $\mathrm{RF}=$ Risk Factors, Positive $=$ with risk of falls in the QuickScreen. Negative $=$ without risk of falls in the QuickScreen. QuickScreen $=$ test performed at baseline. Occurrence of falls $=$ data obtained by monthly phone calls over the six months of the study.

Table 4 describes the ability of the QuickScreen and each risk factor in isolation to predict multiple falls among older women with low BMD over six months of follow-up.

Table 4 - Sensitivity, Specificity, Positive Predictive Value, and Negative Predictive Value of the Quickscreen Clinical Fall Risk Assessment test and each risk factor in older women with low bone density $(n=110)$

\begin{tabular}{lccccc}
\hline Variable & Cutoff point & S (\%) & Sp (\%) & PPV (\%) & NPV (\%) \\
& & & & & \\
\hline QuickScreen & $\geq 2 \mathrm{RF}$ & 73.30 & 33.68 & 14.86 & 88.89 \\
Falls in past year & $\geq 1$ & 53.33 & 57.89 & 16.66 & 88.70 \\
Total medications & $\geq 4$ & 66.67 & 36.84 & 14.28 & 87.50 \\
Psychotropic medication & $\geq 1$ & 33.30 & 72.63 & 16.12 & 87.34 \\
Visual acuity test & Correct reading to the 5th line of the & 13.33 & 92.63 & 22.22 & 87.12 \\
& Snellen chart & & & & \\
Touch sensation test & $\geq 2$ correct perceptions & 0.00 & 97.89 & 0.00 & 86.11 \\
Alternate-step test & $\geq 10 \mathrm{~s}$ & 53.33 & 60.00 & 17.39 & 89.06 \\
Sit-to-stand test & $\geq 12 \mathrm{~s}$ & 40.00 & 65.26 & 15.38 & 87.32 \\
Tandem stand test & $>10 \mathrm{~s}$ & 26.66 & 89.47 & 28.57 & 88.54 \\
\hline
\end{tabular}

Note: $\mathrm{S}=$ Sensitivity; $\mathrm{Sp}=$ Specificity; PPV = Positive Predictive Value; NPV = Negative Predictive Value. 


\section{Discussion}

In the present study, the risk factors for falls at baseline and the occurrence of falls in older women with low BMD over six months of follow-up were evaluated to investigate the predictive validity of the QuickScreen test. Participants were older women, living in the community, septuagenarians, with low levels of education, active, with pre-obesity and the large majority with self-reported cardiac and orthopedic diseases. A high frequency of falls and good accuracy of the QuickScreen to predict falls over six months was observed in this group of older women.

The data relating to the previous history of falls and to falls in only the six month of monitoring showed high incidence of falls in these older women with low BMD when compared to studies that, without control for osteoporosis, showed that, over the period of one year, approximately $30 \%$ of the older adults living in the community fell at least once (8), with half presenting multiple falls $(13,24)$. Additionally, this corroborated the findings of Silva et al. (6), which showed a significantly greater occurrence of falls in osteoporotic women $(51.1 \%)$ than in women without this diagnosis $(29.3 \%)$. Despite the active profile of the sample decreasing the intrinsic risk of falls (25), this same characteristic, added to its female composition, can contribute to increasing the extrinsic risk (26) due to the greater involvement of active women in domestic activities and, consequently, the greater exposure to routine and apparently safe activities during which the majority of falls occur. In this sense, Cruz et al. (10) argued that the higher frequency of falls among older adults with osteoporosis can be directly related to the higher prevalence of osteoporosis among women and those of an advanced age, combined with the possible influence of postural changes, gait disorders and body imbalance. These data indicate the particularity of the group of older women with low BMD and reinforce the importance of the validation of screening instruments for falls in this population.

In this study, the mean of 2.35 risk factors and the presence of risk of falls in the majority of the older women (67\%) corroborated the findings of the study by Tiedemann (17), in which approximately $60 \%$ of the older adults presented 2 to 4 risk factors, with a mean of three risk factors in the total sample. Although the study by Tiedemann (17) also investigated septuagenarians, living in the community, without cognitive impairments, independent in daily activities and with a similar frequency of single (23\%) and multiple (21\%) falls, their sample included older adults of both genders and there was no control for osteoporosis. Similar values were also presented by Ramos and Fonseca (19), who found a mean of 2.8 risk factors in older adults of both genders ( $74.68 \pm 6.28$ years), being $20 \%$ fallers and $32.5 \%$ osteoporotic.

The polypharmacy, the self-report of previous falls and the shifting weight impairment and lateral instability in the alternate-step test were the risk factors most frequent among the older women of the study. These three risk factors demonstrated the limited predictive ability for multiple falls in the analysis of the isolated accuracy of each factor, however, among the eight factors evaluated these were the measures that presented the best predictive values. Ramos and Fonseca (19), using the QuickScreen, also highlighted as the most frequent risk factors among community-dwelling older adults those related to the performance in the alternate-step test (mean of 11.03 seconds) and polypharmacy (55\%), as well as poor performance in the sit-to-stand test (57.5\%, mean of 13.34 seconds). Tiedemann (17) also demonstrated considerable predictive capacity for multiple falls of the alternate-step test, which was able to detect $63 \%$ of the older adults who fell in the 12 months of followup. The one year prospective study of Swanenburg et al. (11) also highlighted a high frequency of polypharmacy (64\%) among multiple fallers, living in the community and septuagenarians (31\% multiple fallers, $28 \%$ osteoporotic). The predictive ability of the use of five or more medications in the older adults of both genders in outpatient care for chronic diseases (35.7\% osteoporotic) was also evidenced by Kojima et al. (27). The experience of falling in the previous twelve months has also been indicated as an important factor for predicting falls in the majority of studies that deal with this line of research $(11,24$, $28,29)$. Therefore, considering the high frequency, the ease of evaluation and the possibility of predicting falls of these three risk factors, their inclusion in future studies regarding screening instruments and in the development of health promotion strategies for osteoporotic older adults should be encouraged.

With regard to the risk factors that were shown to be not as good in predicting falls, the sit-to-stand test, the evaluation of which allows inferences about the muscle strength of the lower limbs and the functional capacity of older adults (30), contrary to expectations, was able to detect only $40 \%$ of the multiple fallers. 
This finding suggests that muscle weakness, among the modifiable factors, can't in isolation characterize a strong risk factor for falls, especially in functionally independent older adults, as highlighted by Meneses, Burke and Marques (31), which should be further investigated considering the controversial findings in the literature $(32,33)$. Evaluations of the use of psychotropic medication, of the tandem stand test and of the peripheral sensitivity test failed to predict falls in isolation, corroborating the findings of Tiedemann, Lord and Sherrington (13) with older adults living in the community and independent, without control for osteoporosis. The poorer predictive ability for multiple falls found in the present study of the visual acuity test compared to the original study may be due to methodological differences regarding the use of the Snellen chart (19) and not the proposed sensitivity to contrast, depth perception and visual field test (13).

Despite the risk factors in isolation showing low predictive accuracy for multiple falls, the findings of this study demonstrate that when analyzed in the multifactorial format of the QuickScreen, using a cutoff of 2 or more risk factors, there was good predictive ability for multiple falls among older women with low BMD. Therefore, although the frequency of the risk factors identified in this study confirmed previous studies with the older general population $(11,17,19,24,27$ - 29), the best cutoff point indicated ( $\geq 2$ risk factors) was lower than that proposed by Tiedemann (17) ( $\geq 4$ risk factors), characterizing an indication of the particularities of the risk of falls in older women with low BMD and the importance of more conservative screening with this population due to increased vulnerability to fractures and reinforcing the need for studies in this line of research.

Despite the low proportion of true negatives among the non-fallers (specificity) and of true positives among the older adults with a positive test (PPV), the high proportion of true positives among the fallers (sensitivity) and of true negatives among the older adults with a negative tests (NPV) showed the good ability of the QuickScreen to identify the majority of older adults who had multiple falls, with low incidence of false negatives, and to correctly identify with negative tests the older adults who did not present multiple falls during the study. Therefore, for screening low BMD older adults the clinical and scientific use of the QuickScreen is recommended. In this context, the investigation of risk of falls screening instruments for older adults is important to reduce false negatives, as the consequences of misidentifying someone that has a risk of falls and, in this case, risk of fractures (possible fallers with low BMD) are greater than providing intervention for someone who has a low risk of falling (34).

However, the predictive values lower than $80 \%$ may have been due to the use of the QuickScreen to predict falls within the six months following its application and not monitoring falls for 12 months, as in the original validation study (13). Considering the theoretical model of the ICF (16) and the multifactorial nature of falls, in addition to the alterations of structure and function investigated, other factors, although difficult to assess and not approached by the QuickScreen, may have predisposed the older women in this sample to the occurrence of falls, such as personal factors - fear of falling (26) and risk behaviors-, factors related to activities (other activities of daily living) and participation (social and family life). Furthermore, the possibility should be considered that the high level of physical activity presented by the older women may have contributed to better performances in the functional tests of the QuickScreen and a reduction in the risk of falls in these tests (25), however, it may have also contributed to increasing their exposure to environmental risks during the study. These limitations, together with the lack of specific studies that used the recent QuickScreen test (13) with older women with low BMD, highlight the difficulty of identifying a single instrument with excellent accuracy for predicting the fall, a multifactorial event, in this specific population $(12,35)$.

Previous studies (36 - 38) have demonstrated that therapeutic exercises of strengthening and balance training are also capable of improving the components of structure and specific function (muscle strength, and static and dynamic balance) and the performance in functional tests in older women with low BMD and, therefore, together with the control of household risk factors, contribute to the prevention falls. Thus, the recommendation to use the QuickScreen as a potential clinical tool able to identify the risk of falls in these older women enables early recognition and referral for further evaluations and physiotherapy services so that they benefit from these interventions (12). It should be noted that this tool stands out from the various instruments with the same purpose, as most existing tools present long application time, require sophisticated equipment, and have been investigated with small samples and through transverse or longitudinal studies with short monitoring periods. 


\section{Conclusion}

This study showed that older women with low BMD present a high frequency of falls and that the QuickScreen clinical instrument was able to predict multiple falls over six months of follow-up. Additionally, the polypharmacy, the self-report of previous falls and impairments in lateral stability were the more predictive risk factors in these older women. Despite the need for more studies in this line of research, the clinical implications of this research relate to the possibility of using the QuickScreen in health promotion programs for osteoporotic and osteopenic older adults. In this moment, in which strong evidence is still lacking, the use of QuickScreen enables not only early identification of the risk of falls, but also the identification of impairments, disabilities and environmental influences where directed physiotherapy interventions can contribute to preventing falls and fractures.

\section{Acknowledgments}

The authors thank Adrienne Vieira and Luciana Louzada for help in the selection of the participants; and Natanny Almeida, Anny Rocha and Danielle Silva for their assistance in the data collection.

\section{References}

1. Pinto Neto AM, Soares A, Urbanetz AA, Souza ACA, Ferrari AEM, Amaral B, et al. Consenso Brasileiro de Osteoporose 2002. Rev Bras Reumatol. 2002;42(6):343-54.

2. Pinheiro MM, Eis SR. Epidemiology of osteoporotic fractures in Brazil: what we have and what we need. Arq Bras Endocrinol Metabol. 2010;54(2):164-70.

3. Smulders E, van Lankveld W, Laan R, Duysens J, Weerdesteyn V. Does osteoporosis predispose falls? A study on obstacle avoidance and balance confidence. BMC Musculoskelet Disord. 2011;12:1.

4. Sinaki M, Brey RH, Hughes CA, Larson DR, Kaufman KR. Balance disorder and increased risk of falls in osteoporosis and kyphosis: significance of kyphotic posture and muscle strength. Osteoporos Int. 2005;16(8):1004-10.

5. Burke TN, França FJR, Meneses SRF, Cardoso VI, Pereira RMR, Danilevicius CF, et al. Postural control among elderly women with and without osteoporosis: is there a diference? Sao Paulo Med J. 2010;128(4):219-24.
6. Silva RB, Costa-Paiva L, Oshima MM, Morais SS, Pinto-Neto AM. Frequency of falls and association with stabilometric parameters of balance in postmenopausal women with and without osteoporosis. Rev Bras Ginecol Obstet. 2009;31(10):496-502.

7. Dontas I, Yiannakopoulos C. Risk factors and prevention of osteoporosis-related fractures. J Musculoskelet Neuronal Interact. 2007;7(3):268-72.

8. Alexandre TS, Meira DM, Rico NC, Mizuta SK. Accuracy of Timed Up and Go Test for screening risk of falls among community-dwelling elderly. Rev Bras Fisioter. 2012;16(5):381-8.

9. Santos GM, Souza AC, Virtuoso JF, Tavares GM, Mazo GZ. Predictive values at risk of falling in physically active and no active elderly with Berg Balance Scale. Rev Bras Fisioter. 2011;15(2):95-101.

10. Cruz DT, Ribeiro LC, Vieira MT, Teixeira MT, Bastos RR, Leite IC. Prevalence of falls and associated factors in elderly individuals. Rev Saude Publica. 2012;46(1):138-46.

11. Swanenburg J, de Bruin ED, Uebelhart D, Mulder T. Falls prediction in elderly people: a 1-year prospective study. Gait Posture. 2010;31(3):317-21.

12. Gates S, Smith LA, Fisher JD, Lamb SE. Systematic review of accuracy of screening instruments for predicting fall risk among independently living older adults. J Rehabil Res Dev. 2008;45(8):1105-16.

13. Tiedemann A, Lord SR, Sherrington C. The development and validation of a brief performance-based fall risk assessment tool for use in primary care. J Gerontol A Biol Sci Med Sci. 2010;65(8):896-903.

14. Garcia PA. Fatores de risco e ferramentas clínicofuncionais de rastreio de risco de quedas em idosas com baixa densidade óssea: um estudo longitudinal [master's thesis]. Belo Horizonte (Brazil): Universidade Federal de Minas Gerais; 2014. Portuguese.

15. Brucki SM, Nitrini R, Caramelli P, Bertolucci PH, Okamoto IH. Sugestões para o uso do mini-exame do estado mental no Brasil. Arq Neuropsiquiatr. 2003;61(3B):777-81.

16. Organização Mundial de Saúde - OMS, Organização Panamericana de Saúde - OPAS. CIF - Classificação Internacional de Funcionalidade, Incapacidade e Saúde. São Paulo: Editora da Universidade de São Paulo; 2003. Portuguese. 
17. Tiedemann A. The development of a validated falls risk assessment for use in clinical practice [master's thesis]. Sydney (Australia): University of New South Wales; 2006. English.

18. Santos FPV, Borges LL, Menezes RL. Correlação entre três instrumentos de avaliação para risco de quedas em idosos. Fisioter Mov. 2013;26(4):883-94.

19. Ramos EC, Fonseca FF. Correlação entre fragilidade e risco de quedas em idosos da comunidade [undergraduate dissertation] Belo Horizonte (Brazil): Universidade Federal de Minas Gerais; 2009. Portuguese.

20. Tiedemann A, Shimada H, Sherrington C, Murray S, Lord S. The comparative ability of eight functional mobility tests for predicting falls in community-dwelling older people. Age Ageing. 2008;37(4):430-5.

21. Pinheiro MM, dos Reis Neto ET, Machado FS, Omura F, Yang JH, Szejnfeld J, et al. Risk factors for osteoporotic fractures and low bone density in pre and postmenopausal women. Rev Saude Publica. 2010;44(3):479-85.

22. Pinheiro MM, Ciconelli RM, Martini LA, Ferraz MB. Risk factors for recurrent falls among Brazilian women and men: the Brazilian Osteoporosis Study (BRAZOS). Cad Saude Publica. 2010;26(1):89-96.

23. Souza AC, Magalhaes LC, Teixeira-Salmela LF. Adaptação transcultural e Análise das propriedades psicométricas da versão brasileira do Perfil de Atividade Humana. Cad Saude Publica. 2006;22(12):2623-36.

24. Perracini MR, Ramos LR. Fatores associados a quedas em uma coorte de idosos residentes na comunidade. Rev Saude Publica. 2002;36(6):709-16.

25. Silva E, Duarte N, Arantes PMM. Estudo da relação entre o nível de atividade física e o risco de quedas em idosas. Fisioter Pesq. 2011;18(1):23-30.

26. Perracini MR, Teixeira LF, Ramos JL, Pires RS, Najas MS. Fall-related factors among less and more active older outpatients. Rev Bras Fisioter. 2012;16(2):166-72.

27. Kojima T, Akishita M, Nakamura T, Nomura K, Ogawa S, Iijima K, et al. Polypharmacy as a risk for fall occurrence in geriatric outpatients. Geriatr Gerontol Int. 2012;12(3):425-30.

28. Komatsu T, Kim KJ, Kaminai T, Okuizumi H, Kamioka H, OkadaS, etal. Clinical factors as predictors of the risk of falls and subsequent bone fractures due to osteoporosis in postmenopausal women. J Bone Miner Metab. 2006;24(5):419-24.
29. Barret-Connor E, Weiss T, Mchorney C, Miller P, Siris E. Predictors of falls among postmenopausal women: resultsfrom the National Osteoporosis Risk Assessment (NORA). Osteoporos Int. 2009;20(5):715-22.

30. Camara FM, Gerez AG, Miranda MLJ, Velardi M. Capacidade Funcional do idoso: formas de avaliação e tendências. Acta Fisiatr. 2008;15(4):249-56.

31. Meneses SRF, Burke TN, Marques AP. Equilíbrio, controle postural e força muscular em idosos osteoporóticas com e sem quedas. Fisioter Pesq. 2012;19(1):26-31.

32. Keskin D, Borman P, Ersoz M, Kurtaran A, Bodur H, Akyuz M. The risk factors related to falling in elderly females. Geriatr Nurs. 2008;29(1):58-63.

33. Moreland JD, Richardson JA, Goldsmith $\mathrm{CH}$, Clase CM. Muscle weakness and falls in older adults: a systematic review and meta-analysis. J Am Geriatr Soc. 2004;52(7):1121-9.

34. Wrisley DM, Kumar NA. Functional gait assessment: concurrent, discriminative, and predictive validity in community-dwelling older adults. Phys Ther. 2010;90(5):761-73.

35. Scott V, Votova K, Scanlan A, Close J. Multifactorial and functional mobility assessment tools for fall risk among older adults in community, home-support, long-term and acute care settings. Age Ageing. 2007;36(2):130-9.

36. Hourigan SR, Nitz JC, Brauer SG, O'Neill S, Wong J, Richardson CA. Positive effects of exercise on falls and fracture risk in osteopenic women. Osteoporos Int. 2008;19(7):1077-86.

37. Murphy L, Singh BB. Effects of 5-Form, Yang Style Tai Chi on older females who have or are at risk for developing osteoporosis. Physiother Theory Pract. 2008;24(5):311-20.

38. Aveiro MC, Granito RN, Navega MT, Driusso P, Oishi J. Influence of a physical training program on muscle strength, balance and gait velocity among women with osteoporosis. Rev Bras Fisioter. 2006;10(4):441-8.

Received in 06/30/2014

Recebido em 30/06/2014

Approved in 10/08/2015

Aprovado em 08/10/2015 